\title{
Correction to: Crystal Structures of Spiro Derivatives Including 6,10-Dioxaspiro[4.5]decane-7,9-dione Group and Their Spectral Studies
}

Wulan Zeng ${ }^{1} \cdot$ Xia Wang $^{1}$

Published online: 5 January 2019

(c) Springer Science+Business Media, LLC, part of Springer Nature 2019

Correction to: Journal of Chemical Crystallography https://doi.org/10.1007/s10870-018-0746-y

The original version of this article unfortunately contains the error in reaction Scheme 1 Graphical Abstract and inside text.

The correct version of index abstract and the text is given below.

\section{Graphical Abstract}

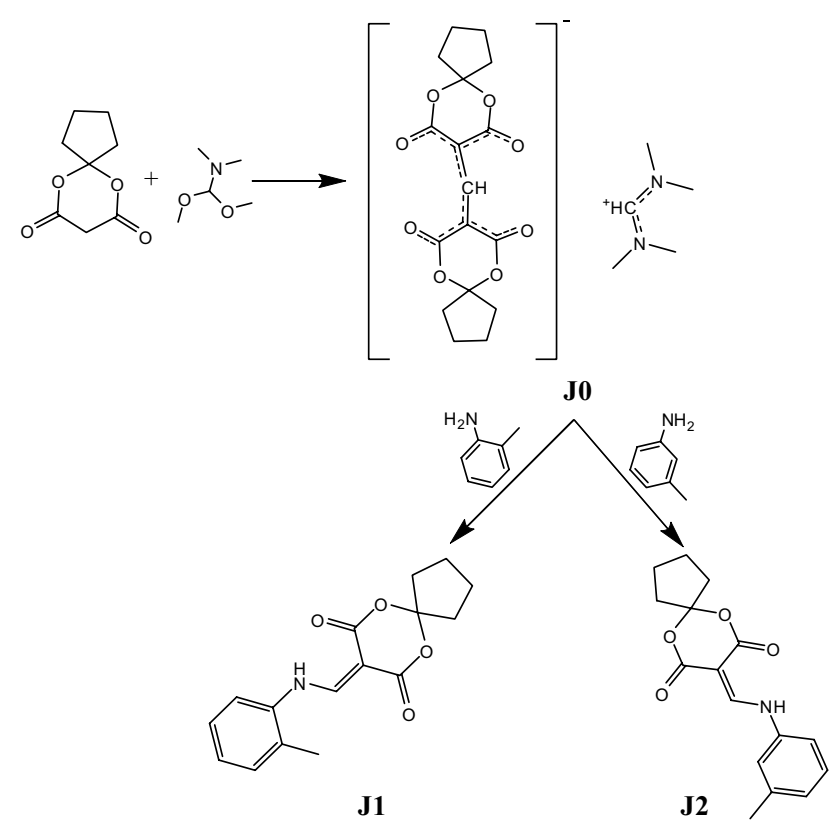

In the introduction section, the sentence last before one, the word Scheme 1 should read as New Scheme 1.

The original article can be found online at https://doi.org/10.1007/ s10870-018-0746-y.

Wulan Zeng

wulanzeng@163.com

1 Department of Chemistry, Chemical Engineering and Environmental Engineering, Weifang University, Weifang 261061, China 